\title{
A Near-Death Experience Followed by the Visitation of an "Angel-Like" Being
}

\author{
Richard J. Bonenfant, Ph.D. \\ Gainesville, FL
}

ABSTRACT: I describe a near-death experience (NDE) followed by a religious experience 15 years later in which the subject was visited by the same "angellike" figure that she saw in the NDE. I describe details of the NDE and of the subsequent visitation; note transformational changes in behavior and associated aftereffects; examine childhood experiences possibly related to the NDE; review the presence of angels in Biblical and mystical literature and in contemporary media; and suggest a possible relationship between latent paranormal abilities and the occurrence of a variety of exceptional experiences.

The following case was brought to my attention while I was conducting research on the duration of aftereffects resulting from near-death experiences (NDEs). The case was self-reported in the "Remarks" section of a survey instrument by a 31-year-old white woman residing in Upstate New York. The subject is currently married and employed as a research manager for individuals with mentally retardation. I conducted several follow-up interviews with the subject to prepare this account for publication.

\section{The Near-Death Experience}

The initial event occurred during a house party held at the subject's home in the summer of 1981. At the time, the subject was swimming in a long "Florida-shaped" pool. Over a period of years she had trained herself to swim the entire length of the pool underwater. On this particular

Richard J. Bonenfant, Ph.D., is a retired medical researcher with the Congenital Malformations Registry at the New York State Department of Health and an Adjunct Instructor in the Department of Computer Science at Sienna College in Loudonville, NY. Reprint requests should be addressed to Dr. Bonenfant at 6008 S.W. 86 th Drive, Gainesville, Florida 32608 . 
occasion, she had reached the deep end of the pool and kicked off the wall for her return lap just as a drunken partygoer jumped into the pool directly above her. In playfulness he grabbed the subject, dragging her to the bottom of the pool. Since the subject had just completed her first lap underwater, she had no reserve air in her lungs, and during the struggle to free herself from the man's grasp she quickly lost consciousness.

What followed was a classic NDE. The subject found herself slowly drifting upwards in a dark environment. Although still disoriented and confused, she no longer felt the fear, distress, and panic of drowning. She was now comfortable and fully alert in her new surroundings. The subject reported that she felt herself gently rising at an oblique angle, as if she were riding an invisible escalator. As she became accustomed to the darkness, she was able to perceive depth within that darkness. Next, she witnessed a childhood scene involving her still-living younger sister. The vision appeared briefly against a dark background, in vivid color, and was framed within a rectangular television-like format. In this scene, the younger sister was about 3 or 4 years old, had pigtails, and was playing with their family cat. That scene was immediately followed by another one involving a deceased family dog named Pepper. The second scene was described as being similar to the first one in appearance. Neither scene was accompanied by any sound. The subject then became aware of a distant light located slightly above and ahead of her. The light appeared small and distant at first but grew in brightness and size as she progressed toward it. While moving towards the light, the subject felt that she was passing through a dark tunnel, slowly at first, but later with great acceleration. As she moved within the light she was filled with awe, peace, and love.

The subject discerned, framed within the light, the figure of "a beautiful woman" with hands outstretched to receive her. This woman was described as being clothed in a white dress, and having long, darkblonde hair and blue eyes. The angelic being radiated a sense of "motherly love" to the subject. The subject remarked that her only desire was to reach the safety of those outstretched hands. But when she was nearly within reach, the figure withdrew her hands and told the subject, through her eyes, that is was not yet her time and that she would have to return.

Almost immediately, the subject found herself back in her physical body gasping for breath on the deck of the swimming pool. Apparently, she had been rescued and pulled out of the pool onto the deck while undergoing her NDE. A total of about two minutes had elapsed since 
she had lost consciousness. No medical treatment was administered and she recovered without any evident physical harm from the drowning accident.

\section{The Visitation}

The second part of this account involves the return of the same angellike entity 15 years later. On August 17, 1996, the subject's daughter was invited to attend a party at her friend's house. The host of this event owned a dog who had apparently been taunted over the years by spray from a garden hose. At one point during the event, the subject's daughter was standing near the garden hose when she accidentally tripped over it, causing the hose to flip up and strike the dog. The dog immediately reacted by attacking the subject's daughter, tearing a large section of flesh from the daughter's left cheek. Needless to say, the attack was extremely traumatic to both mother and daughter. Several major operations involving skin grafts were required to repair the damaged facial area.

After one such operation, the subject was comforting her daughter while they both rested in the mother's bed. The subject recalled that her daughter had been having nightmares and was thrashing about. To protect the newly grafted area, she cradled her daughter's face in her arms as they lay together. It was late at night and the room was dark. Then, suddenly, a subdued light appeared behind the subject's left shoulder. She immediately turned her head about to determine the source of the illumination. There was no evident explanation for the light, but when she returned her gaze toward her daughter, she saw the identical "beautiful woman" who had appeared to her during her NDE. The angel-like figure was only a couple of feet away. Her head was resting on her arms at the edge of the bed. Gazing at both mother and daughter, the angel communicated telepathically to the mother that she was not to worry because her daughter would be all right. The subject was awestruck by the encounter and briefly closed her eyes to refocus them upon the being, but when she reopened her eyes the figure was gone.

When questioned about the identity of this female entity, the subject was absolutely sure that it was the same angel-like being that she had observed during her earlier NDE. There was only one minor difference. In the visitation, the angel's hair was "up" about her head rather than falling down below her shoulders. The second appearance was very brief, lasting only several seconds, and the subject observed only 
the head, shoulders and arms of the angelic figure. As a result of the visitation, the subject was not only comforted that her daughter would recover, but became convinced that "a personal relationship" existed between herself and the lady-in-white. To the subject, this being was her own special "guardian angel."

\section{Discussion}

The subject's NDE included the following prototypical core elements: (1) being in a dark environment, (2) feeling peaceful and calm, (3) passage through a dark tunnel toward a distant light, (4) encountering a being of light, (5) being overcome with a feeling of unconditional love while in the presence of the light, (6) being instructed to return, and (7) experiencing a reluctance to return. In addition, while a life review did not present itself, images did emerge from the subject's past life while in the dark void. The subject reported 13 of the 16 items on the NDE Scale (Greyson, 1983), with a total score of 26 . Her subscale scores of the NDE Scale were 4 on the Cognitive Component, 8 on the Affective Component, 18 on the Paranormal Component, and 8 on the Transcendental Component, meeting the criteria for a Transcendental Type NDE (Greyson, 1985).

The images reported in this NDE differed from those of a prototypic life review. While the scenes were of real events that had happened in her past, they did not suggest any judgmental evaluation of the subject's life. Rather, they appeared to be random scenes without relation to her NDE situation. When asked about their significance, the subject responded that they failed to convey any sense or reason. She was not particularly attached either to her younger sister or to her dog Pepper. However, the scenes did reflect memories of events that had actually transpired in her past.

The subject characterized her NDE as a peak experience. It influenced her perception of death in the classical manner: she reported that she no longer had any fear of death or dying. The NDE caused her to become more loving towards others, and to replace interest in traditional worldly pursuits with a desire to provide service to those in need. Learning and formal education had always been important to the subject, but their importance intensified following her NDE. In general, the subject felt that changes in her attitudes and behavior resulting from her NDE were dynamic, and that they have become stronger with the passage of time. 
The subject's religious background was unremarkable. She reported having been raised without religious affiliation by a Catholic mother and an atheist father. No religious propensities were evident prior to either the NDE or the visitation. The NDE confirmed her pre-existing beliefs in God and an afterlife, but it did not result in any increase in religious behavior. Her spirituality was expressed through care of the disadvantaged. During interviews, the subject gave numerous examples of how she was able to provide care and assistance to patients that far exceeded the boundaries of her professional responsibilities as a research manager. This service, coupled with an intuitive ability to recognize individuals in distress, have been hallmarks in her life since the NDE.

Several researchers, including Kenneth Ring and Christopher Rosing (1990) and William Serdahely (1993), have suggested that many NDErs report a history of childhood abuse. The subject of this report did not claim to have been abused, but did report having been emotionally neglected. While her parents were financially affluent, she had received little attention from them. She remembered feeling very lonely as a child and complained that her parents "didn't even know I existed." On several occasions she had hidden beneath her bed for hours hoping that her parents would become concerned over her absence and seek to find her; but they never did. When she attempted to capture her father's attention, he would avoid the occasion by giving her money to "go shopping." The subject characterized her childhood as one of emotional isolation and loneliness.

Changes in attitudes, values, and behavior resulting from the NDE have been persistent with one notable exception. The subject reported that her faith in the goodness of God had been severely tested by the dog attack upon her daughter. Following the attack, she questioned why a loving God would permit such a thing to happen to an innocent child. She recalled being angry over what seemed to be a terrible injustice. The subject felt that it was this very dilemma that precipitated the visitation by her guardian angel. The visitation reassured her that God was aware of her anguish, and that $\mathrm{He}$ had sent her guardian angel to affirm His concern and to restore her faith.

Many of these changes and aftereffects have become stronger over time. In this case, the exercise of intuition and service appeared to have achieved synergistic results. For example, success in the ability to recognize those in emotional need, coupled with dedication to provide service to such individuals, has intensified over the years. An example of this continuing concern for others was demonstrated by her recent efforts to speak to nursing care patients about her own near-death experience 
in hopes of providing them with firsthand reassurance about what lies ahead.

She also reported several specific aftereffects previously described by P. M. H. Atwater (1988): (1) her wristwatch always runs too fast, (2) her eyes are extremely sensitive to sunlight and fluorescent lights, (3) light bulbs frequently dim or burn out in her presence, and (4) various psychic manifestation are very common in her life.

Our interviews uncovered a history of psychic experiences prior to her NDE. She reported having seen the spirits of two deceased women in her parents' house on many occasions during her childhood. These ghostly figures appeared to both the subject and her sister. The spirits apparently recognized each family member but never "haunted" them in a traditional sense. The subject claimed that the figures were easily distinguishable, one being a blonde and the other a brunette. They were dressed in late 19th century garb and appeared to be attached to the house they were living in. She reported that these visions only occurred in their parent's house and that no comparable visions appeared to her following her departure from that residence.

The existence of pre-NDE psychic talents raises the possibility that such abilities may predispose paranormally gifted individuals to undergo a variety of exceptional human experiences during their lifetimes, including both NDEs and religious or mystical experiences. The association between NDEs and spiritual experiences dates back to the foundation of near-death studies, with many researchers considering NDEs to be simply another form of spiritual experiences. Even if this view oversimplifies some aspects of NDE phenomenology, few would question the prominence of the spiritual component of NDEs. While the case reported above progresses in a sequence from paranormal to NDE to religious experiences, any combination of these events may prove to be equally valid. The occurrence of psychic experiences is well recognized following NDEs, but it would be interesting to review NDE accounts for the occurrence of such experiences prior to the reported NDEs.

\section{The Presence of Angels in NDEs}

Angels have played an important role in the religious traditions of Western society. The word "angel" is derived from the Greek word angelos, which literally means "messenger." They are considered to be spiritual beings, superior to humans in power and intelligence, who act as agents of God. Angels are portrayed in art as being human in form, with 
long, white wings, clothed in white vestments, and often with a halo about their head. NDErs who have had encounters with angels report that they have a beautiful countenance, and radiate a sense of peace, serenity, trust, and love. Craig Lundahl (1992) discussed at length the function of angels during NDEs, concluding that they inform, guide, and protect human beings during their transition to the afterlife.

Angels are ubiquitous in the literature of many religions. They are acknowledged in the Jewish Talmud, the Christian Bible, and the Islamic Koran. More two hundred references to angels can be found in the King James version of the Bible, divided evenly between the Old and New Testaments, although one quarter of those references are contained in the Book of Revelations. In addition, the presence of angels has frequently been reported in the visions of religious saints and mystics. Pierre Jovanovic (1993) has carefully documented many of these encounters in his review of Western historical records. The Swedish scientist and mystic Emanuel Swedenborg extensively discussed his own personal encounters with angels in many of his theological works; a summary of Swedenborg's views about angels has been recently published by Robert Kirven (1994). This long tradition of interaction with angels continues into recent times. The contemporary Greek Orthodox mystic Vassula Ryden (1992, 1995) has reported numerous conversations with her own guardian angel.

A resurgence of interest in angels during the past decade may be partially attributed to their popularity in contemporary media. Many recent books on angels have cascaded off of the popularity of Sophy Burnham's Book of Angels (Burnham, 1990); there are currently more than 1800 in print. In the visual media, television series such as Highway to Heaven and Touched by an Angel, and recent movies like City of Angels (Silberling, 1998) and What Dreams May Come (Ward, 1998) have served to maintain a focus on the topic of angels in the public's mind. This popularity was documented in a 1993 survey conducted by Time magazine (Gibbs and Chua-Eoan, 1993), which revealed that 69 percent of the 500 individuals polled believed in angels, 46 percent believed in the existence of personal guardian angels, and 32 percent reported having had some form of actual contact with angels.

By contrast, I was able to uncover only two articles in the professional literature on the topic of angels. In one, Lundahl (1992, p. 49) wrote that "the literature on near-death experiences (NDEs) contains no substantive discussion of angels in NDEs, even though there are references to angels in several studies of these experiences." Lundahl identified 
references to angels in the works of Raymond Moody (Moody, 1975; Moody and Perry, 1988), Kenneth Ring (1982), and George Gallup and William Proctor (1982), as well as in his own work (Lundahl, 1982). There was one additional article on angels published in the nursing literature, describing three cases and suggesting helpful nursing interventions with patients who describe encounters with angels (Kennard, 1998).

Angel experiences occur to children and adults, males and females, and to those of nonreligious as well as religious backgrounds. Jovanovic (1993) noted that in his historic review of religious and mystical experiences 70 percent of the visions of angels occurred to women. A few sample quotes from the near-death literature will serve to illustrate what is being reported by NDErs in their encounters angels.

Following are two adult examples of angelic encounters. The first, reported by Brad Steiger (1994), reflected the experience of a woman named Gloria and described how an angel led her toward the light during a NDE. After hearing the sound of bells, she reported that her guardian angel came down through the ceiling for her. This angelic being accompanied Gloria toward a bright light that appeared to be shining in the center of a great expanse of darkness. According to this witness (Steiger, 1994, p. 49):

It was the most beautiful and compelling light that I had ever seen. My angel nodded at me as I hesitated to draw nearer. "Yes," the angelic being said. "We must now become One with the Light so that we may ascend higher."

The second adult account of an angel was reported by Maurice Rawlings (1978). In this account the witness's thoughts were examined by a bright angel (p. 69):

I knew I was dying. They had just gotten me to the hospital and then I felt this pain in my head and I saw a great light and everything was whizzing around and around. Then I felt free and at peace and just had an uncanny sense of well being. I looked down on the medical people working over me and it didn't bother me a bit. I wondered why.

Then I was suddenly enveloped in this black cloud and went through this tunnel. I emerged from the other end in a white light which had a soft glow. There was my brother who had died three years previously. I attempted to go through a doorway, but my brother was blocking my view and wouldn't let me see what was behind him.

Then I saw what was behind him. It was a bright angel. An angel of light. I felt encompassed by this force of love from this angel that was searching and probing my deepest thoughts. I was being searched and 
then I seemed to be allowed to sense the presence of spirits of some other loved ones who died previously. Then my whole body jumped upward from the electric jolt they gave me, and I knew I was back on earth again.

Since I have recovered from this encounter with death, I am no longer afraid of death.

Among contemporary NDEs, many of the most touching accounts of angels have come from children. Melvin Morse has documented many such childhood accounts in Closer to the Light (Morse and Perry, 1990), including that of 9-year-old Katie, who encountered an angel named Elizabeth during her passage through a dark tunnel. Katie described Elizabeth as being tall and nice with bright golden hair. The angel accompanied Katie through the tunnel into the light where she met several deceased relatives and friends. Later, Elizabeth presented Katie to the Heavenly Father and to Jesus.

Mary Kennard (1998) reported a more recent encounter by another 9-year-old girl named Mallory who was diagnosed with terminal cancer (p. 50):

She knew she was dying and she was very afraid. One morning, she told her mother that three angels had come to her during the night. The angels had white wings and were very beautiful. They'd taken her on a trip to heaven. Mallory wasn't sick in the presence of the angels and even danced with them.

Nine days before she died, Mallory made a videotape for other terminally ill children. She described the angels and heaven so that the children would not be afraid of death. She told them, "Believe what I say because it's true. It really is."

To my knowledge, the question of how frequently NDErs report having encounters with angels has not been studied. Anecdotal accounts of angels do appear in the literature, but there has been no systematic evaluation of such reports to determine the relative frequency of angel encounters. Through examination of sporadic accounts in the professional literature, and from a limited sample of NDE accounts I have been collecting for a study of NDE aftereffects, I propose an incidence rate of about 4 percent. However, this rate may underestimate the number of angelic encounters in childhood NDEs.

\section{Conclusion}

The most interesting aspect of the account presented above is that it suggests the existence of a personal relationship between the NDEr 
and an angel-like being. While only a single case, it tends to support the traditional concept of a guardian angel. A review of the literature revealed that in spite of the popularity of angels in current media, there is a paucity of professional information concerning angels in NDEs. The absence of an organized collection of observations on angelic encounters undermines attempts to draw conclusions about their nature or significance.

Is there a correlation between the existence of pre-NDE paranormal abilities and the likelihood of undergoing an NDE or other exceptional experiences? This subject's vision of spirit beings prior to both her NDE and her angel encounter suggests that psychic abilities may be a factor underlying these separate events. Examination of pre-NDE psychic experiences in future studies could shed light on the possibility that individuals with inherent paranormal talents are predisposed to having a variety of unusual human experiences.

\section{References}

Atwater, P. M. H. (1988). Coming back to life: The after-effects of the near-death experience. New York: Dodd-Mead.

Burnham, S. (1990). A book of angels: Reflections on angels past and present and true stories of how they touch our lives. New York: Ballantine.

Gallup, G., and Proctor, W. (1982). Adventures in immortality: A look beyond the threshold of death. New York: McGraw-Hill.

Gibbs, N., and Chua-Eoan, H. G. (1993, December 27). Angels among us. Time, 142(27), $56-65$.

Greyson, B. (1983). The near-death experience scale: Construction, reliability, and validity. Journal of Nervous and Mental Disease, 171, 369-375.

Greyson, B. (1985). A typology of near-death experiences. American Journal of Psychiatry, $142,967-969$.

Jovanovic, P. (1993). An inquiry into the existence of guardian angels: A journalist investigative report. New York: M. Evans.

Kennard, M. J. (1998). A visit from an angel. American Journal of Nursing, 98(3), 4851.

Kirven, R. H. (1994). Angels in action: What Swedenborg saw and heard. West Chester, PA: Chrysalis Books.

Lundahl, C. R. (1982). Near-death experiences of Mormons. In C. R. Lundahl (Ed.), A collection of near-death research readings (pp. 165-179). Chicago: Nelson-Hall.

Lundahl, C. R. (1992). Angels in near-death experiences. Journal of Near-Death Studies, $11,49-56$.

Moody, R. A. (1975). Life after life. Covington, GA: Mockingbird Books.

Moody, R. A., and Perry, P. (1988). The light beyond. New York: Bantam.

Morse, M., and Perry, P. (1990). Closer to the light: Learning from the near-death experiences of children. New York: Villard.

Rawlings, M. (1978). Beyond death's door. Nashville, TN: Thomas Nelson.

Ring, K., and Rosing, C. J. (1990). The omega project: An empirical study of the NDE-prone personality. Journal of Near-Death Studies, 8, 211-239. 
Ring, K. (1992). The omega project: Near-death experiences, UFO encounters, and mind at large. New York: Morrow.

Ryden, V. (1992). True life in God [Video]. Independence, MO: Trinitas.

Ryden, V. (1995). My Angel Daniel. Independence: MO, Trinitas.

Serdahely, W. J. (1993). Near-death experiences and dissociation: Two cases. Journal of Near-Death Studies, 12, 85-94.

Silberling, B. (Dir.). (1998). City of angels [Film]. Hollywood, CA: Warner.

Steiger, B. (1994). One with the light. New York: Penguin.

Ward, V. (Dir.). (1998). What dreams may come [Film]. Hollywood, CA: Polygram. 